\title{
Repeated trips by patients seeking medical treatment overseas from the United Arab Emirates: Results from the Dubai Health Authority during 2009-2016
}

\section{Wafa K. Alnakhi ( $\square$ wkalnakhi@gmail.com )}

Johns Hopkins University Bloomberg School of Public Health https://orcid.org/0000-0003-2875-4173

Omamh A. Alfarisi

Kuwait University Faculty of Pharmacy

\section{Bareng A. S Nonyane}

Johns Hopkins University Bloomberg School of Public Health

\section{Laura L. Morlock}

Johns Hopkins University Bloomberg School of Public Health

\section{Saifuddin Ahmed}

Johns Hopkins University Bloomberg School of Public Health

\section{Research article}

Keywords: Overseas treatment, Medical travel, Travel medicine, Follow-up care, Repeated medical trips, Public Health, Health policy, Healthcare services, Health services research, Healthcare management, United Arab Emirates

Posted Date: February 11th, 2020

DOI: https://doi.org/10.21203/rs.2.23164/v1

License: (c) (1) This work is licensed under a Creative Commons Attribution 4.0 International License. Read Full License 


\section{Abstract}

Background: The Dubai Health Authority (DHA) spends millions of dollars to cover United Arab Emirates (UAE) nationals seeking healthcare overseas each year. Many patients undertake multiple visits following their initial trip. This paper analyzes repeated trips following an initial medical trip overseas so that the DHA can more effectively address patients' needs and reduce the risks associated with multiple trips overseas.

Methods: Administrative data were obtained from the DHA for the UAE nationals who sought treatment overseas during 2009-2016. We examined the match of the medical specialty between the initial and subsequent trips. Medical specialty was the key independent variable and other covariates included gender, age group, travel season, treatment destination and trip order. A mixed-effects logistic regression model with subject specific random intercept was used to assess the relationship of the outcome with the key variables of interest.

Results: The analysis included 2,344 UAE nationals who had at least one trip following the initial medical visit. Oncology was the most common medical specialties sought by patients who travelled for repeated visits (18\%). Patients in the age group 13-18 years had the highest odds of subsequent visits matching the medical specialty at the initial trip relative among age groups (OR 1.93, 95\% Cl:1.351,2.757). Patients travelling for oncology, orthopedic surgery, neurosurgery, ophthalmology, obstetrics/gynecology and otolaryngology had higher odds of subsequent trips matching the specialty of initial trips. The odds of subsequent trips matching the medical specialty of the initial trip increased with each additional trip (OR $1.73,95 \% \mathrm{Cl}: 1.533,1.94)$.

Conclusions: This is the first longitudinal study that examines the repeated medical trips among UAE nationals supported by the DHA. The results demonstrated that age group, medical specialty sought at the time of the initial trip, and number of trips were significant factors for understanding the match of the medical specialty between the initial and subsequent trips. The study results may help the DHA to establish an overseas treatment registry to collect information about patients seeking medical treatment overseas. In addition, the study will support establishing follow-up care programs to improve patients' outcome and the clinical care for those patients.

\section{Introduction}

The demand for global healthcare services is experiencing tremendous growth (1-7). Each year, the Dubai Health Authority (DHA) - the government health entity that oversees healthcare services in the Emirate of Dubai - spends an average of 77 million US dollars to cover the costs for an average of 1500 UAE national patients seeking healthcare overseas (8). The health sector in Dubai comprises government facilities [1], private facilities, and a free zone[2] (9). Although the government of Dubai provides free healthcare services to UAE nationals at public health facilities, which is mandated by law, a number of patients travel to seek healthcare services outside the UAE. Since there are many governmental entities in 
the UAE and in Dubai other than the DHA that sponsor UAE nationals for treatment overseas, the number of these patients is not accurately enumerated and cannot be easily traced.

Patients travelling overseas for healthcare seek an array of treatment options ranging from preventive procedures to complex surgeries(10). In addition, patients travel to different treatment destinations ranging from low-middle income countries to high income countries (11-14). The treatment destinations sought for healthcare services are determined by patients and their families, often in consultations with physicians. As per the government law in the Emirate of Dubai, any Emirati citizens, irrespective of their socioeconomic status, are eligible to seek healthcare services overseas. Seeking treatment overseas with government coverage is conditioned by the unavailability of treatment in the government/public sector or by the belief that a better option exists overseas. A patient seeking health care overseas must provide a valid medical report from a physician in one of the DHA healthcare facilities stating the unavailability of optimal treatment in the government sector. The patient must sign and agree to government rules and regulations for the treatment plan at the treatment destination. This agreement states that patients should stay under the supervision of the DHA at all times to be granted final approval and financial coverage during the overseas treatment period.

Obtaining healthcare services overseas may be associated with risks and complications to patients compared with obtaining healthcare domestically (15). Receiving routine follow-up treatment may also be challenging for many of these patients especially when multiple follow-up care visits are required overseas. Certain medical specialties require multiple follow-up visits or a long course of therapy for some conditions (16). Given the high cost of medical services overseas, the potential risks associated with multiple trips abroad and the availability of free healthcare services in the UAE, it is important to analyze the repeated medical trips following the initial trip. (17-20). Our key interest is to identify the medical specialties with more repeated trips. This analysis was performed by matching the specialty between the initial and subsequent trips. The study results will provide valuable information for the DHA to establish follow-up care policies and programs for the patients seeking healthcare overseas. In addition, these results will aid in improving the policies for patients with multiple trips ensuring that these repeated trips are addressing patients' needs. Moreover, these findings may help to reduce the risks of exacerbating patients' health problems due to repeated trips not addressing the reasons for the initial trip overseas. $(21,22)$

[1] The government healthcare sector in Dubai consists of two entities: Dubai Health Authority (DHA) and Ministry of Health $(\mathrm{MOH})$. DHA is the health authority that is responsible for the healthcare in the Emirate of Dubai only. $\mathrm{MOH}$ is the federal health authority that is responsible for the healthcare in all the Emirates.

[2] Free-trade zones (FTZs) are special economic zones established with the objective of offering tax concessions and customs duty benefits to expatriate investors. 


\section{Methods}

\subsection{Data Source, Study Design, Variables and Measures}

Administrative data of UAE nationals who sought medical treatment overseas during the period 2009 2016 under the sponsorship of the DHA were obtained from the DHA. The data contained the following information: birth date, gender, departure date, medical specialty sought overseas, and treatment destinations. Birth date was converted to a categorical variable with 7 age groups based on patterns of association between the medical specialty sought and age. Medical specialty was defined as the specialty for which patients sought medical treatment at the treatment destination and used as a categorical variable consisting of 42 medical conditions. The American Board of Medical Specialties' categories were used to improve standardization and increase precision. Patients who had more than one medical specialty reported in the DHA records for a given trip during $2009-2016$ were removed from the analysis (3.2\%). Three new variables were created from the departure date: number of trips, trip order, and travel season. Number of trips is a discrete variable and defined as the total number of trips taken by a patient to treatment destinations during the study period. Trip order is another discrete variable to reflect the sequence number of each trip during the study period for each patient. Travel season is a categorical variable with 4 seasons and defined as the season during which a patient travelled for treatment overseas. Treatment destination, a categorical variable with 22 countries, defined as the treatment destination a patient traveled to for medical diagnosis/treatment overseas. The outcome of interest is binary and defined as whether the medical specialty a patient sought treatment for during subsequent trips matched the medical specialty of the initial trip overseas.

\subsection{Ethical Issues}

The study protocol was submitted to the Johns Hopkins School of Public Health Institutional Review Board where it was defined as not involving human subjects research (IRB No: 00007896).

\subsection{Statistical Analysis}

Descriptive statistics were used to examine the independent variables. We applied mixed-effects logistic regression models with subject specific random intercepts and robust standard errors for examining the matching of medical specialty between the initial and subsequent trips for a given set of covariates, including the types of medical specialties (23). Our mixed-effects logistic regression models were adjusted for clustering due to multiple observations and hierarchically fitted for potential confounders. Results were reported with odds ratios (ORs) to identify factors associated with matching the medical specialty at the initial and subsequent trips, with $95 \%$ confidence intervals $(\mathrm{Cl})$ and p-values $<0.05$ indicating statistical significance (24). The covariates in the models included gender, age group, medical specialty, travel season, treatment destinations and trip order. The variance inflation factor (VIF) was performed to ensure absence of significant collinearity among independent variables. The mean VIF was less than 2 which indicated there was no significant collinearity. Our analysis model is illustrated below: 


$$
Y_{i j} \log \operatorname{match}\left(\frac{P i j}{1-P i j}\right) \mid b_{0}=\beta_{0}+\sum_{J=1}^{J} \beta_{j} x_{i j}+\mu_{i j}
$$

\footnotetext{
Where $\left(Y_{i j}\right)$ is the expected log odds of the medical specialty in the follow up trips matching the

medical specialty at the initial trip. $\left(b_{0}\right)$ a patient's random intercept. $(\beta)$ regression coefficient.

$\left(x_{i}\right)$ covariates. (j) number of trips. (i) patients with at least one trip following their initial trip.

$\left(\mu_{i j}\right)$ indicates a patient's specific deviation.
}

The statistical analyses were conducted by using Stata 13 (Stata Corporation, College Station TX).

\section{Results}

\section{Descriptive Statistics}

There were 2,344 patients who had at least one trip following their initial trip when seeking healthcare services overseas from the United Arab Emirates through the Dubai Health Authority during 2009 - 2016. The frequencies of study variables are shown in Table 1. Patients aged $19-39$ were the largest age group (28.2\%). Among the top 15 medical specialties that patients sought treatment for oncology and orthopedic surgery had the highest number of repeated trips (18.0\% and $12.7 \%$ respectively). The most common destinations patients travelled overseas for were Germany (45.6\%), followed by the UK (18.2\%).

The mean, median and maximum number of trips are shown in Table 2. Although patients aged 19-39 years had the maximum number of trips (19), patients aged 5-12 years had the highest mean value of trips (mean 2.61, SD1.84). Among the top 15 medical specialties, patients who travelled for nephrology had the largest maximum number (19) with the highest mean number of trips (mean 3.25, SD 3.43). Among the top 7 treatment destinations, patients who travelled to the USA had the largest maximum number of trips (19) with the highest mean number of trips (mean 2.85, SD 1.98). The majority of patients had one trip following their initial trip $(n=1,289)$ as shown in Figure 1.

\section{The odds of matching the medical specialty between the initial and subsequent trips}

Unadjusted and adjusted odds ratios (ORs) from the mixed-effects logistic regression models are shown in Table 3. A patient in the age group of 13-18 years had the highest odds of the medical specialty matching between the initial and subsequent trips relative to a patient in the youngest age group of 0 - 4 years given the same underlying propensity of matching the medical specialty (OR 1.93, 95\%Cl:1.351,2.757). Patients in other age groups, including 19-39 years, 40-54 years, and 55-69 years also had higher odds of the medical specialty matching between the initial and subsequent trips relative to the reference group. The odds of repeated visits for the same medical specialty decreased with age for age groups older than 18 years after adjusting for covariates. 
After adjusting for covariates, patients who initially travelled overseas for oncology, orthopedic surgery, neurosurgery, ophthalmology, obstetrics/gynecology and otolaryngology had higher odds of seeking these specialties on subsequent trips relative to patients who initially travelled for other medical specialties not included among the most frequent 15 medical specialties for which patients sought treatment. On the other hand, patients who initially sought medical treatment overseas for a medical specialty not specified in the DHA records, had lower odds of seeking the same medical specialty during subsequent trips relative to patients who initially travelled for other medical specialties not included in the top 15 specialties after adjusting for covariates (OR $0.14,95 \% \mathrm{Cl}: 0.069,0.262)$. The odds of the medical specialty matching with the initial trip increased with every additional follow-up trip (OR $1.73,95 \% \mathrm{Cl}$ : $1.533,1.94)$.

\section{Discussion}

The majority of patients in our study had two trips following their initial trip. Study results indicate that the repeated trips for some medical specialties were significantly more likely to match the medical specialty at the initial trip. Patients who initially sought medical treatment overseas for oncology, orthopedic surgery, neurosurgery, ophthalmology, obstetrics/gynecology and otolaryngology were more likely to travel again for the same medical specialty. On the other hand, a patient seeking treatment overseas with unknown medical condition and not specified in the DHA records was less likely to match the subsequent trips with the initial trip. Age group and the number of additional trips were factors influencing traveling again seeking advice and/or treatment for the same medical specialty.

Patients who travelled overseas for healthcare sought a range of treatment options. Some treatment options might necessitate follow-up care more than others as a part of the treatment regimen. Although our results illustrated the generally positive association of age with repeated visits for the same medical specialty, the odds of the medical specialty matching between initial and subsequent trips decreased for older age groups. Due to lacking medical visit details, it was not possible to distinguish the purpose of subsequent visits. As a result of aging, older individuals are more prone to multiple chronic diseases, may experience health decline and are at risk of complications (25-27). While these factors were not captured by our study, they may explain why the odds of seeking the same medical specialty in subsequent trips decreased in older age groups. More information is needed to better understand the relationship between age and patterns of healthcare seeking abroad.

Ophthalmology was one of the top 15 medical specialties that patients sought medical treatment for overseas. Our previous study has shown that patients travelling overseas specifically for this medical specialty had a higher than expected number of trips during the period $2009-2016$ compared to other medical specialties (28). Although there are insufficient clinical studies about ophthalmology in the UAE, some research has linked ophthalmology visits to the association between diabetes mellitus and retinopathy (29-32). Currently the prevalence of diabetes in the UAE is among the highest in the world (33). Complications of diabetes mellitus could be one cause of seeking healthcare overseas for 
ophthalmology, although to understand the extent to which there is a relationship, more information is needed than there is available in the administrative dataset.

Our study demonstrated that patients who initially sought medical treatment overseas for oncology or orthopedic surgery were more likely to have subsequent trips for the same medical specialty. In general, there are a lack of clinical and pathological studies in the UAE related to cancers, or to orthopedic or spine surgeries (34-37). However, some studies have been conducted on rheumatoid arthritis showing a gap between the onset of the disease and timely referral to appropriate treatment options (38-40). Orthopedic surgery is the second most common medical specialty in our study for which patients sought treatment overseas with relatively high odds of subsequent trips being made for the same specialty relative to other medical specialties for which treatment was sought. However, the lack of information in the administrative data regarding reasons for travel, such as diseases classified according to international standards, makes it difficult to identify the different medical conditions that led to seeking orthopedic surgery, including whether it was due to arthritis, injuries or other conditions.

Similarly, our administrative data lacked sufficient details regarding the underlying conditions of patients seeking treatment regarding neurosurgery, obstetrics/ gynecology and otolaryngology. As a result, it was difficult to determine what led to seeking treatment overseas for these medical specialties. However our previous research in understanding the motivational factors for choosing treatment destinations indicated that stroke (brain hemorrhage) is one of the factors for seeking medical treatment overseas (41, 42). Stroke is a multifactorial disease in which a combination of risk factors can influence the probability overtime of a person experiencing this condition. Hypertension, diabetes mellitus, cardiovascular disease, life style, smoking and previous transient ischemic attack are risk factors associated with stroke or brain hemorrhage that may lead to neurosurgery (43). Stroke could be one cause of seeking medical treatment overseas for neurosurgery; brain tumors, or neurodegenerative diseases or other medical conditions could also be involved $(44,45)$.

Patients who travelled overseas for medical treatment sponsored by the Dubai Health Authority travelled to a number of different destinations. Currently there is no prospective registry at the DHA that captures comprehensive information related to the overseas treatment of patients. A registry focusing on the overseas treatment of patients should be designed to capture patients' socio-demographic profiles, disease specific characteristics, breakdown of expenditures, treatment destination details, and patient reported outcomes. This is necessary for future research and establishing cost-effective policies (46). Our results demonstrated that 6 out of 15 of the most frequent medical specialties for which treatment is initially sought overseas are more likely to have subsequent trips for the same medical specialty compared to medical specialties for which overseas treatment is sought less frequently. Additional research should begin by focusing on these top medical specialties.

Among the top 7 treatment destinations, $79 \%$ of the patients travelled to high income destinations such as Germany, UK, USA, Singapore, and Spain[1]. To ensure that patients' needs are met during the repeated trips and their medical conditions are managed effectively, measuring the value of care received overseas 
is necessary. A report including the detailed expenditures of each trip should be mandatory. Aggregating and analyzing such information will help guide the government in establishing future comparative and cost-effectiveness studies. These studies will help to assess the extent to which resources allocated to overseas treatment are being utilized optimally and are obtaining the best value for the healthcare expenditures (47-50).

We acknowledge some limitations of our study. The data collected from the DHA did not include international classification of disease codes or information about the severity and type of diseases for which overseas treatment was sought. However, the American Medical Specialty Board classification of medical specialties was used to accomplish some standardization in data management. In addition, patients who had more than one medical specialty reported in the DHA records during the study period for a given trip were excluded from the analysis with the assumption they could potentially introduce a bias to the analysis. The exclusion decision was made due to the inability to access patients' records for further information in order to know the primary medical specialty the patient sought healthcare for overseas. Using previously collected administrative data limited the ability to access additional variables that could explain the patterns in care seeking detected. Since the study was limited to patients sponsored through the Dubai Health Authority only, we cannot generalize the results to patients sponsored by other health authorities in the UAE such as the Ministry of Health and the Department of Health in Abu Dhabi.

However, the availability of these data is considered a strength since it can begin to provide some guidance in order to improve the policies and strategies related to sponsoring overseas treatment. Establishing a registry that contains all the essential variables would prepare the government for conducting future research to measure patient outcomes after receiving treatment overseas. For example, measuring pre and post-operative health status following treatment overseas through patient-reported outcome assessment could guide clinical care following overseas treatment (51-53). Accordingly, followup care programs could be tailored to address the needs of patients after the overseas experience based on medical specialty guidelines regarding appropriate follow-up time and required therapy (54). In the future, different types of telemedicine could be explored, as a substitute to follow-up overseas using patient assessments, monitoring and outcomes reporting (55). The results of this study can suggest some areas for the government to provide treatment options in the UAE, whether in the government or the private sector, or through establishing public-private partnerships. This step could help channel patients toward better utilization of the private sector in the UAE as an alternative to overseas treatment.

[1] High income destination: a country with high gross national income (GNI) as per the World Bank country classification

\section{Conclusion}


This is the first longitudinal study related to overseas treatment in the UAE and therefore contributes to the limited empirical research in the field of travel medicine. The results demonstrated that age group, medical specialty sought at the time of the initial trip, and number of trips were significant factors for understanding whether repeated trips were made to seek treatment for the same medical specialty. Creating an overseas treatment registry is an important next step to capture comprehensive information related to patients' travelling for healthcare services overseas. Measuring patient outcomes through patient reported outcome tools is important to guide the clinical care of patients following their overseas experience. Follow-up care programs are essential to help assure high quality patient outcomes and the cost-effective use of resources. In the future, telemedicine could be explored as one strategy of providing a substitute to the risks associated with treatment overseas and could allow patients to utilize the services provided in the public and private sectors within the UAE (56-60).

\section{Declarations}

\section{Ethical approval}

The study protocol was approved by the Johns Hopkins School of Public Health Institutional Review Board, which determined the study to be not human subjects research (IRB No: 00007896) given the use of previously collected administrative data without patient identifiers.

\section{Consent for publication}

Not applicable.

\section{Availability of data and materials}

The data that support the findings of this study are from the Dubai Health Authority. However, restrictions apply to the availability of these data, which were used under special agreement for the current study; thus, these data are not publicly available. Data are available from the corresponding author upon reasonable request and with permission of the Dubai Health Authority.

\section{Competing interests}

The authors declare that they have no competing interests.

\section{Funding}

This research did not receive any specific grant from funding agencies in the public, commercial, or notfor-profit sectors. However, we would like to express our gratitude to the Ministry of Higher Education and Scientific Research in the United Arab Emirates for their financial support during the doctoral degree period and support in conducting this research. We thank the Dubai Health Authority for supporting the publication of this research as a part of a postdoctoral fellowship.

\section{Authors' contributions}


WA collected the data from the Dubai Health Authority, analyzed the data and drafted the manuscript as part of a post-doctoral fellowship. OA and BA contributed in the data management and longitudinal analysis. SA and LM substantially revised the paper and approved the submitted version to the journal.

\section{Acknowledgments}

We acknowledge the staff at the Dubai Health Authority who supported access to the data for the purpose of conducting this research as a part of a doctoral thesis and postdoctoral fellowship. We thank Arjun Gupta an Oncology Fellow, Johns Hopkins Sidney Kimmel Comprehensive Cancer Center for providing literature on cancer follow up and management. We would like also to acknowledge support for the statistical analysis from the National Center for Research Resources and the National Center for Advancing Translational Sciences (NCATS) of the National Institutes of Health through Grant Number 1UL1TR001079.

\section{References}

1. Burkett L. Medical tourism. Concerns, benefits, and the American legal perspective. J Leg Med. 2007;28(2):223-45.

2. Smith RD, Chanda R, Tangcharoensathien V. Trade in health-related services. The Lancet. 2009;373(9663):593-601.

3. Eissler LA, Casken J. Seeking health care through international medical tourism. Journal of Nursing Scholarship. 2013;45(2):177-84.

4. Forgione DA, Smith PC. Medical tourism and its impact on the US health care system. J Health Care Finance. 2007;34(1):27-35.

5. Henson JN, Guy BS, Dotson MJ. Should I stay or should I go?: Motivators, decision factors, and information sources influencing those predisposed to medical tourism. International Journal of Healthcare Management. 2015;8(1):4-14.

6. Smith PC, Forgione D.A. Global outsourcing of healthcare: a medical tourism decision model. Journal of Information Technology Case and Application Research. 2007;9(3):19-30.

7. Lunt N, Horsfall D, Hanefeld J. Medical tourism: A snapshot of evidence on treatment abroad. Maturitas. 2016;88:37-44.

8. Authority DH. Dubai Health Authority Annual Statistic Reports of 2004 - 2015. 2016.

9. Dubai Health Authority. Insurance System for Advancing Healthcare in Duabi. 2014.

10. Authority DH. Dubai Health Authority Annual Statistic Reports of 2009 - 2016. 2016 - 2017.

11. Koornneef EJ, Robben PB, Al Seiari MB, Al Siksek Z. Health system reform in the emirate of Abu Dhabi, United Arab Emirates. Health policy. 2012;108(2-3):115-21.

12. The Official Portal of the UAE Government. Travelling abroad for medical treatment 2019.

13. GULF NEWS. Lack of speciality hospitals forcing Emiratis to travel abroad. 2018.

14. United Arab Emirates Ministry of Health \& Prevention. Request Treatment Abroad. 2019, April 
15. McCallum BT, and Philip F. Jacoby. Medical outsourcing: Reducing clients' health care risks. Journal of Financial Planning. 2007;20(10):60-9.

16. Khatcheressian JL, et al. Breast cancer follow-up and management after primary treatment: American Society of Clinical Oncology clinical practice guideline update. J Clin Oncol [internet] 2012.

17. Cohen IG. How to regulate medical tourism. 2012.

18. Cohen IG. Patients with passports: medical tourism, law, and ethics: New York, NY: Oxford University Press; 2014.

19. Crooks VA, Turner L, Cohen IG, Bristeir J, Snyder J, Casey V, et al. Ethical and legal implications of the risks of medical tourism for patients: a qualitative study of Canadian health and safety representatives' perspectives. BMJ open. 2013;3(2):e002302 doi: 10.1136/bmjopen-2012-.

20. Turner LG. Quality in health care and globalization of health services: accreditation and regulatory oversight of medical tourism companies. International Journal for Quality in Health Care. 2010;23(1):1-7.

21. Miedema B, MacDonald I, Tatemichi S. Cancer follow-up care. Patients' perspectives. Canadian Family Physician. 2003;49(7):890-5.

22. Group AAoPSoHOCsO. Long-term follow-up care for pediatric cancer survivors. Pediatrics. 2009;123(3):906-15.

23. Thomas R, Have T, Kunselman AR, Pulkstenis EP, Landis JR. Mixed effects logistic regression models for longitudinal binary response data with informative drop-out. Biometrics. 1998:367-83.

24. Youngquist ST. Part 19: What is a P value? Air medical journal. 2012;31(2):56-71.

25. Vellas BJ, Albarede J-L, Garry PJ. Diseases and aging: patterns of morbidity with age; relationship between aging and age-associated diseases. The American journal of clinical nutrition. 1992;55(6):1225S-30S.

26. Williams SR, Pham-Kanter G, Leitsch SA. Measures of chronic conditions and diseases associated with aging in the national social life, health, and aging project. Journals of Gerontology Series B: Psychological Sciences and Social Sciences. 2009;64(suppl_1):i67-i75.

27. Fulop T, Larbi A, Witkowski JM, McElhaney J, Loeb M, Mitnitski A, et al. Aging, frailty and age-related diseases. Biogerontology. 2010;11(5):547-63.

28. Alnakhi WK, Segal JB, Frick KD, Hussin A, Ahmed S, Morlock L. Treatment destinations and visit frequencies for patients seeking medical treatment overseas from the United Arab Emirates: results from Dubai Health Authority reporting during 2009-2016. Tropical Diseases, Travel Medicine and Vaccines. 2019;5(1):10.

29. Al-Maskari F, El-Sadig M, Norman JN. The prevalence of macrovascular complications among diabetic patients in the United Arab Emirates. Cardiovascular diabetology. 2007;6(1):24.

30. Al-Maskari F, El-Sadig M. Prevalence of diabetic retinopathy in the United Arab Emirates: a crosssectional survey. BMC ophthalmology. 2007;7(1):11. 
31. Sheikh-Ismail LI, Henry CJK, Lightowler HJ, Aldhaheri AS, Masuadi E, Al Hourani HM. Prevalence of overweight and obesity among adult females in the United Arab Emirates. International journal of food sciences and nutrition. 2009;60(sup3):26-33.

32. Al-Maskari F, El-Sadig M. Prevalence of risk factors for diabetic foot complications. BMC family practice. 2007;8(1):59.

33. Whiting DR, Guariguata L, Weil C, Shaw J. IDF diabetes atlas: global estimates of the prevalence of diabetes for 2011 and 2030. Diabetes research and clinical practice. 2011;94(3):311-21.

34. Baeesa SS, Maghrabi Y, Msaddi AK, Assaker R. Quality of spine surgery research from the Arab countries: A Systematic review and bibliometric analysis. BioMed research international. 2017;Biomed Res Int 2017:7560236.

35. Khoja T, A. Zahrani, and Tawfik AM Khoja. Epidemiology of cancer in the Gulf Region. Pan Arab J Oncology. 2010;3(1):8-10.

36. Salim El, Moore MA, Al-Lawati JA, Al-Sayyad J, Bazawir A, Bener A, et al. Cancer epidemiology and control in the arab world-past, present and future. Asian Pac J Cancer Prev. 2009;10(1):3-16.

37. Tadmouri G, Al Ali M, Al Khaja N. Genetic Disorders in the Arab World: United Arab Emirates. Centre for Arab Genomic Studies, Dubai, UAE. 2004.

38. Moufarrej MN, Mahfoud Z, Badsha H. Barriers to achieving controlled rheumatoid arthritis in the United Arab Emirates: a cross-sectional study. Rheumatology international. 2015;35(4):759-63.

39. Halabi H, Alarfaj A, Alawneh K, Alballa S, Alsaeid K, Badsha H, et al. Challenges and opportunities in the early diagnosis and optimal management of rheumatoid arthritis in A frica and the $M$ iddle $E$ ast. International journal of rheumatic diseases. 2015;18(3):268-75.

40. Badsha H, Kong KO, Tak PP. Rheumatoid arthritis in the United Arab Emirates. Clinical rheumatology. 2008;27(6):739-42.

41. Alnakhi WK. Patients from the United Arab Emirates Seeking Healthcare Services Overseas During 2009-2016: Characteristics, Motivational Factors and Preferences: Johns Hopkins University; 2018.

42. Tran J, Mirzaei M. The population attributable fraction of stroke associated with high blood pressure in the Middle East and North Africa. Journal of the neurological sciences. 2011;308(1-2):135-8.

43. Behrouz R, Powers CJ. Epidemiology of classical risk factors in stroke patients in the Middle East. European journal of neurology. 2016;23(2):262-9.

44. DeAngelis LM. Brain tumors. New England Journal of Medicine. 2001;344(2):114-23.

45. Bjarkam CR, Sørensen JC, Sunde NÅ, Geneser FA, Østergaard K. New strategies for the treatment of Parkinson's disease hold considerable promise for the future management of neurodegenerative disorders. Biogerontology. 2001;2(3):193-207.

46. Nelson EC, Dixon-Woods M, Batalden PB, Homa K, Van Citters AD, Morgan TS, et al. Patient focused registries can improve health, care, and science. BMJ. 2016;354:i3319.

47. Bank TW. World Bank Country Classifications 2018 [Available from: https://datahelpdesk.worldbank.org/knowledgebase. 
48. Damman OC, Spreeuwenberg P, Rademakers J, Hendriks M. Creating compact comparative health care information: what are the key quality attributes to present for cataract and total hip or knee replacement surgery? Medical Decision Making. 2012;32(2):287-300.

49. Chalkidou K, Whicher D, Kary W, Tunis S. Comparative effectiveness research priorities: identifying critical gaps in evidence for clinical and health policy decision making. International journal of technology assessment in health care. 2009;25(3):241-8.

50. Sox HC, Greenfield S. Comparative effectiveness research: a report from the Institute of Medicine. Annals of internal medicine. 2009;151(3):203-5.

51. Garcia SF, Cella D, Clauser SB, Flynn KE, Lad T, Lai J-S, et al. Standardizing patient-reported outcomes assessment in cancer clinical trials: a patient-reported outcomes measurement information system initiative. Journal of clinical oncology. 2007;25(32):5106-12.

52. Purvis TE, Neuman BJ, Riley III LH, Skolasky RL. Can Early Patient-reported Outcomes Be Used to Identify Patients at Risk for Poor 1-Year Health Outcomes After Lumbar Laminectomy With Arthrodesis? Spine. 2018;43(15):1067-73.

53. Skolasky RL, Albert TJ, Vaccaro AR, Riley III LH. Patient satisfaction in the cervical spine research society outcomes study: relationship to improved clinical outcome. The Spine Journal. 2009;9(3):232-9.

54. Del Giudice ME, Grunfeld E, Harvey BJ, Piliotis E, Verma S. Primary care physicians' views of routine follow-up care of cancer survivors. Journal of clinical oncology. 2009;27(20):3338-45.

55. Saliba V, Legido-Quigley H, Hallik R, Aaviksoo A, Car J, McKee M. Telemedicine across borders: a systematic review of factors that hinder or support implementation. International journal of medical informatics. 2012;81(12):793-809.

56. Kitamura C, L. Zurawel-Balaura, and R. K. S. Wong. How effective is video consultation in clinical oncology? A systematic review. Current oncology. 2010;17(3):17.

57. Dickinson R, et al. Using technology to deliver cancer follow-up: a systematic review. BMC cancer. 2014;14(1):311.

58. Al-Qirim N. Realizing telemedicine advantages at the national level: cases from the United Arab Emirates. Telemedicine and e-Health. 2007;13(5):545-56.

59. Hazin R, and Ibrahim Qaddoumi. Teleoncology: current and future applications for improving cancer care globally. The lancet oncology. 2010;11(2):204-10.

60. Qaddoumi I, et al. Impact of telemedicine on pediatric neuro-oncology in a developing country: The Jordanian-Canadian experience. Pediatric blood \& cancer. 2007;48(1):39-43.

\section{Tables}

Table 1. Baseline sociodemographic characteristics and trip characteristics for patients from the United Arab Emirates who had at least one trip following their initial trip overseas for medical treatment sponsored by the Dubai Health Authority during 2009 - 2016 


\begin{tabular}{|c|c|}
\hline Characteristic & $\mathrm{N}(\%)$ \\
\hline \multicolumn{2}{|l|}{ Gender } \\
\hline Male & $1,169(49.9)$ \\
\hline Female & $1,175(50.1)$ \\
\hline \multicolumn{2}{|l|}{ Age Group } \\
\hline $0-4$ yrs. & $286(12.2)$ \\
\hline $5-12$ yrs. & $196(8.4)$ \\
\hline $13-18$ yrs. & $126(5.4)$ \\
\hline $19-39$ yrs. & $660(28.2)$ \\
\hline 40-54 yrs. & $481(20.5)$ \\
\hline 55-69yrs. & $441(18.8)$ \\
\hline $70+$ & $154(6.6)$ \\
\hline \multicolumn{2}{|l|}{ Medical Specialty } \\
\hline Internal Medicine: Oncology & $421(18.0)$ \\
\hline Orthopedic Surgery & $298(12.7)$ \\
\hline Neurosurgery & $209(8.9)$ \\
\hline Ophthalmology & $157(6.7)$ \\
\hline Neurology & $129(5.5)$ \\
\hline Internal Medicine: Cardiology & $99(4.2)$ \\
\hline General Surgery & $88(3.8)$ \\
\hline Obstetrics and Gynecology & $90(3.8)$ \\
\hline Un specified Pediatrics & $91(3.9)$ \\
\hline Internal Medicine: Gastroenterology & $75(3.2)$ \\
\hline Urology & $64(2.7)$ \\
\hline Not Specified Cases & $44(1.9)$ \\
\hline Internal Medicine: Endocrinology & $43(1.8)$ \\
\hline Internal Medicine: Nephrology & $45(1.9)$ \\
\hline Otolaryngology & $45(1.9)$ \\
\hline Other Medical Specialties* & $446(19.0)$ \\
\hline \multicolumn{2}{|l|}{ Travel Season } \\
\hline Summer & $640(27.3)$ \\
\hline Fall & $508(21.7)$ \\
\hline Winter & $533(22.7)$ \\
\hline Spring & $663(28.3)$ \\
\hline \multicolumn{2}{|l|}{ Treatment Destination } \\
\hline Germany & $1,068(45.6)$ \\
\hline UK & $426(18.2)$ \\
\hline Thailand & $349(14.9)$ \\
\hline USA & $164(7.0)$ \\
\hline Singapore & $95(4.1)$ \\
\hline Spain & $88(3.8)$ \\
\hline India & $71(3.0)$ \\
\hline Other destinations $* *$ & $83(3.5)$ \\
\hline Total & $2,344(100.0)$ \\
\hline
\end{tabular}

Page $14 / 20$ 
*Urology, Not Specified Cases, Internal Medicine: Endocrinology, Internal Medicine, Otolaryngology, Thoracic Surgery, Internal Medicine: Hematology, Pediatrics: Cardiology, Internal Medicine: Nephrology, Pediatrics: Neurology, Internal Medicine: Pulmonology, Pediatrics: Surgery, Plastic Surgery, Internal Medicine: Rheumatology, Vascular Surgery, Pediatrics: Oncology, Dermatology, Pediatrics: Neurosurgery, Pediatrics: Nephrology, Physical Medicine and Rehabilitation, Screening \& Check-up, Pediatrics: Gastroenterology, Pediatrics: Hematology, Pediatrics: Neonatology, Psychiatry, Oral \& Maxillofacial Surgery, Dental, Pediatrics: Rheumatology, Pediatrics: Endocrinology, Genetics, Internal Medicine: Infectious Diseases, Pediatrics: Pulmonology

** Republic of Austria, Kingdom of Belgium, French Republic, Republic of Slovenia, Swiss Confederation, People's Republic of China, Korea, Kingdom of Saudi Arabia, Republic of the Philippines, Arab Republic of Egypt, The Hashemite Kingdom of Jordan, Czech Republic, Italian Republic, Kingdom of Sweden, Republic of Turkey

Table 2. Mean, median and maximum number of trips for patients from the United Arab Emirates with repeated visits overseas for medical treatment sponsored by the Dubai Health Authority during 2009 2016 


\begin{tabular}{|c|c|c|c|}
\hline Characteristics & Mean (SD) & Median (IQR) & Maximum Trips \\
\hline \multicolumn{4}{|l|}{ Gender } \\
\hline Male & $2.53(1.91)$ & $2(1-3)$ & 19 \\
\hline Female & $2.33(1.52)$ & $2(1-3)$ & 12 \\
\hline \multicolumn{4}{|l|}{ Age Group } \\
\hline 0-4 yrs. & $2.52(1.84)$ & $2(1-3)$ & 16 \\
\hline 5-12 yrs. & $2.61(1.84)$ & $2(1-3)$ & 11 \\
\hline $13-18$ yrs. & $2.27(1.44)$ & $2(1-3)$ & 10 \\
\hline 19-39 yrs. & $2.41(1.86)$ & $2(1-3)$ & 19 \\
\hline $40-54$ yrs. & $2.47(1.68)$ & $2(1-3)$ & 13 \\
\hline 55-69yrs. & $2.37(1.56)$ & $2(1-3)$ & 11 \\
\hline $70+$ & $2.30(1.59)$ & $2(1-3)$ & 10 \\
\hline \multicolumn{4}{|l|}{ Medical Specialty } \\
\hline Internal Medicine: Oncology & $2.95(2.02)$ & $2(1-4)$ & 13 \\
\hline Orthopedic Surgery & $2.16(1.32)$ & $2(1-3)$ & 9 \\
\hline Neurosurgery & $2.09(1.39)$ & $2(1-2)$ & 11 \\
\hline Ophthalmology & $2.43(1.69)$ & $2(1-3)$ & 10 \\
\hline Neurology & $2.17(1.33)$ & $2(1-3)$ & 9 \\
\hline Internal Medicine: Cardiology & $2.55(1.72)$ & $2(1-3)$ & 12 \\
\hline General Surgery & $2.10(1.29)$ & $2(1-3)$ & 8 \\
\hline Obstetrics and Gynecology & $1.99(1.12)$ & $2(1-3)$ & 6 \\
\hline Un specified Pediatrics & $2.07(1.20)$ & $2(1-3)$ & 8 \\
\hline Internal Medicine: Gastroenterology & $2.11(1.18)$ & $2(1-3)$ & 6 \\
\hline Urology & $2.15(1.32)$ & $2(1-3)$ & 8 \\
\hline Not Specified Cases & $2.82(1.98)$ & $2(1-4)$ & 11 \\
\hline Internal Medicine: Endocrinology & $2.08(1.19)$ & $2(1-3)$ & 6 \\
\hline Internal Medicine: Nephrology & $3.25(3.43)$ & $2(1-4)$ & 19 \\
\hline Otolaryngology & $2.09(1.32)$ & $2(1-3)$ & 10 \\
\hline Other Medical Specialties* & $2.48(1.84)$ & $2(1-3)$ & 16 \\
\hline \multicolumn{4}{|l|}{ Travel Season } \\
\hline Summer & $2.45(1.81)$ & $2(1-3)$ & 19 \\
\hline Fall & $2.39(1.74)$ & $2(1-3)$ & 16 \\
\hline Winter & $2.41(1.70)$ & $2(1-3)$ & 18 \\
\hline Spring & $2.48(1.67)$ & $2(1-3)$ & 14 \\
\hline \multicolumn{4}{|l|}{ Treatment Destination } \\
\hline Germany & $2.38(1.71)$ & $2(1-3)$ & 16 \\
\hline $\mathrm{UK}$ & $2.40(1.72)$ & $2(1-3)$ & 17 \\
\hline Thailand & $2.43(1.71)$ & $2(1-3)$ & 13 \\
\hline USA & $2.85(1.98)$ & $2(2-4)$ & 19 \\
\hline Singapore & $2.53(1.70)$ & $2(1-3)$ & 9 \\
\hline Spain & $2.13(1.28)$ & $2(1-3)$ & 8 \\
\hline India & $2.57(1.94)$ & $2(1-3)$ & 12 \\
\hline Other destinations $* *$ & $2.54(1.70)$ & $2(1-3)$ & 12 \\
\hline
\end{tabular}


*Urology, Not Specified Cases, Internal Medicine: Endocrinology, Internal Medicine, Otolaryngology, Thoracic Surgery, Internal Medicine: Hematology, Pediatrics: Cardiology, Internal Medicine: Nephrology, Pediatrics: Neurology, Internal Medicine: Pulmonology, Pediatrics: Surgery, Plastic Surgery, Internal Medicine: Rheumatology, Vascular Surgery, Pediatrics: Oncology, Dermatology, Pediatrics: Neurosurgery, Pediatrics: Nephrology, Physical Medicine and Rehabilitation, Screening \& Check-up, Pediatrics: Gastroenterology, Pediatrics: Hematology, Pediatrics: Neonatology, Psychiatry, Oral \& Maxillofacial Surgery, Dental, Pediatrics: Rheumatology, Pediatrics: Endocrinology, Genetics, Internal Medicine: Infectious Diseases, Pediatrics: Pulmonology

** Republic of Austria, Kingdom of Belgium, French Republic, Republic of Slovenia, Swiss Confederation, People's Republic of China, Korea, Kingdom of Saudi Arabia, Republic of the Philippines, Arab Republic of Egypt, The Hashemite Kingdom of Jordan, Czech Republic, Italian Republic, Kingdom of Sweden, Republic of Turkey

Table 3. Unadjusted and adjusted odds ratios of matching medical specialties between the initial and subsequent trips overseas of patients from the United Arab Emirates sponsored by the Dubai Health Authority during $2009-2016$ 


\begin{tabular}{|c|c|c|c|c|c|c|}
\hline \multirow[t]{2}{*}{ Independent Variable } & \multicolumn{3}{|c|}{ Unadjusted } & \multicolumn{3}{|c|}{ Adjusted } \\
\hline & OR & $95 \% \mathrm{CI}$ & P-Value & OR & $95 \% \mathrm{CI}$ & P-Value \\
\hline \multicolumn{7}{|c|}{ Gender } \\
\hline Female & 1.00 & - & - & 1.00 & - & - \\
\hline Male & 0.96 & $(0.861,1.081)$ & 0.535 & 0.94 & $(0.826,1.072)$ & 0.358 \\
\hline \multicolumn{7}{|c|}{ Age group } \\
\hline $0-4$ yrs & 1.00 & - & - & 1.00 & - & - \\
\hline $5-12$ yrs & 1.29 & $(0.990,1.689)$ & 0.060 & 1.29 & $(0.914,1.814)$ & 0.148 \\
\hline $13-18$ yrs & 1.80 & $(1.344,2.402)$ & $<0.001$ & 1.93 & $(1.351,2.757)$ & $<0.001$ \\
\hline $19-39$ yrs & 1.64 & $(1.341,2.016)$ & $<0.001$ & 1.84 & $(1.370,2.480$ & $<0.001$ \\
\hline $40-54$ yrs & 1.71 & $(1.380,2.116)$ & $<0.001$ & 1.74 & $(1.287,2.340)$ & $<0.001$ \\
\hline $55-69$ yrs & 1.34 & $(1.078,1.677)$ & $<0.001$ & 1.39 & $(1.022,1.890)$ & 0.036 \\
\hline $70+\mathrm{yrs}$ & 1.25 & $(0.925,1.688)$ & 0.147 & 1.31 & $(0.915,1.864)$ & 0.141 \\
\hline \multicolumn{7}{|c|}{ Medical Specialty } \\
\hline Other medical specialties* & 1.00 & - & - & 1.00 & - & - \\
\hline Internal Medicine Oncology & 2.14 & $(1.764,2.592)$ & $<0.001$ & 1.47 & $(1.105,1.954)$ & 0.008 \\
\hline Orthopedic Surgery & 1.50 & $(1.239,1.809)$ & $<0.001$ & 1.56 & $(1.218,1.999)$ & $<0.001$ \\
\hline Neurosurgery & 1.41 & $(1.145,1.727)$ & 0.001 & 1.47 & $(1.131,1.905)$ & 0.004 \\
\hline Ophthalmology & 2.41 & $(1.939,3.003)$ & $<0.001$ & 2.12 & $(1.40,3.209)$ & $<0.001$ \\
\hline Neurology & 1.11 & $(0.862,1.416)$ & 0.431 & 0.99 & $(0.716,1.372)$ & 0.956 \\
\hline Internal Medicine: Cardiology & 1.22 & $(0.902,1.664)$ & 0.194 & 1.03 & $(0.708,1.496)$ & 0.882 \\
\hline General Surgery & 1.02 & $(0.762,1.364)$ & 0.896 & 0.98 & $(0.669,1.429)$ & 0.909 \\
\hline Obstetrics and Gynecology & 1.54 & $(1.199,1.965)$ & 0.001 & 1.45 & $(1.063,1.989)$ & 0.019 \\
\hline Unspecified Pediatrics & 0.81 & $(0.600,1.090)$ & 0.164 & 1.23 & $(0.800,1.883)$ & 0.349 \\
\hline Internal Medicine: Gastroenterology & 1.24 & $(0.918,1.682)$ & 0.160 & 1.19 & $(0.816,1.734)$ & 0.368 \\
\hline Urology & 0.95 & $(0.669,1.339)$ & 0.756 & 1.01 & $(0.641,1.588)$ & 0.971 \\
\hline Specialty Not Specified & 0.27 & $(0.171,0.420)$ & $<0.001$ & 0.14 & $(0.069,0.262)$ & $<0.001$ \\
\hline Internal Medicine: Endocrinology & 0.93 & $(0.618,1.409)$ & 0.7430 & 0.86 & $(0.553,1.351)$ & 0.523 \\
\hline Internal Medicine: Nephrology & 1.52 & $(0.963,2.409)$ & 0.072 & 0.98 & $(0.413,2.320)$ & 0.961 \\
\hline
\end{tabular}




\begin{tabular}{|c|c|c|c|c|c|c|}
\hline Otolaryngology & 1.63 & $(1.168,2.271)$ & 0.004 & 1.79 & $(1.195,2.672)$ & 0.005 \\
\hline \multicolumn{7}{|c|}{ Travel Season } \\
\hline Summer & 1.00 & - & - & 1.00 & - & - \\
\hline Fall & 0.95 & $(0.814,1.100)$ & 0.471 & 0.94 & $(0.798,1.117)$ & 0.505 \\
\hline Winter & 0.98 & $(0.845,1.127)$ & 0.738 & 0.99 & $(0.842,1.157)$ & 0.874 \\
\hline Spring & 1.11 & $(0.965,1.275)$ & 0.146 & 1.13 & $(0.965,1.330)$ & 0.128 \\
\hline \multicolumn{7}{|c|}{ Treatment Destination } \\
\hline Other destinations** & 1.00 & - & - & 1.00 & - & - \\
\hline Germany & 0.83 & $(0.624,1.116)$ & 0.224 & 0.85 & $(0.624,1.150)$ & 0.287 \\
\hline UK & 0.87 & $(0.636,1.192)$ & 0.388 & 0.95 & $(0.683,1.328)$ & 0.773 \\
\hline Thailand & 0.92 & $(0.673,1.257)$ & 0.601 & 1.165 & $(0.836,1.625)$ & 0.367 \\
\hline USA & 1.17 & $(0.812,1.673)$ & 0.406 & 0.944 & $(0.633,1.411)$ & 0.781 \\
\hline Singapore & 1.43 & $(0.967,2.101)$ & 0.073 & 1.23 & $(0.806,1.87)$ & 0.340 \\
\hline Spain & 1.78 & $(1.246,2.532)$ & 0.001 & 1.33 & $(0.791,2.22)$ & 0.285 \\
\hline India & 1.09 & $(0.711,1.663)$ & 0.700 & 1.04 & $(0.666,1.630)$ & 0.858 \\
\hline \multicolumn{7}{|c|}{ Number of Trips } \\
\hline Trips & 1.71 & $(1.522,1.913)$ & $<0.001$ & 1.73 & $(1.533,1.94)$ & $<0.001$ \\
\hline
\end{tabular}

*Urology, Not Specified Cases, Internal Medicine: Endocrinology, Internal Medicine, Otolaryngology, Thoracic Surgery, Internal Medicine: Hematology, Pediatrics: Cardiology, Internal Medicine: Nephrology, Pediatrics: Neurology, Internal Medicine: Pulmonology, Pediatrics: Surgery, Plastic Surgery, Internal Medicine: Rheumatology, Vascular Surgery, Pediatrics: Oncology, Dermatology, Pediatrics: Neurosurgery, Pediatrics: Nephrology, Physical Medicine and Rehabilitation, Screening \& Check-up, Pediatrics: Gastroenterology, Pediatrics: Hematology, Pediatrics: Neonatology, Psychiatry, Oral \& Maxillofacial Surgery, Dental, Pediatrics: Rheumatology, Pediatrics: Endocrinology, Genetics, Internal Medicine: Infectious Diseases, Pediatrics: Pulmonology

** Republic of Austria, Kingdom of Belgium, French Republic, Republic of Slovenia, Swiss Confederation, People's Republic of China, Korea, Kingdom of Saudi Arabia, Republic of the Philippines, Arab Republic of Egypt, The Hashemite Kingdom of Jordan, Czech Republic, Italian Republic, Kingdom of Sweden, Republic of Turkey

\section{Figures}




\section{Distribution of Trips Following the Initial Trip among Patients Treated Overseas from The United Arab Emirates Sponsored by The Dubai Health Auhority during 2009 - 2016}

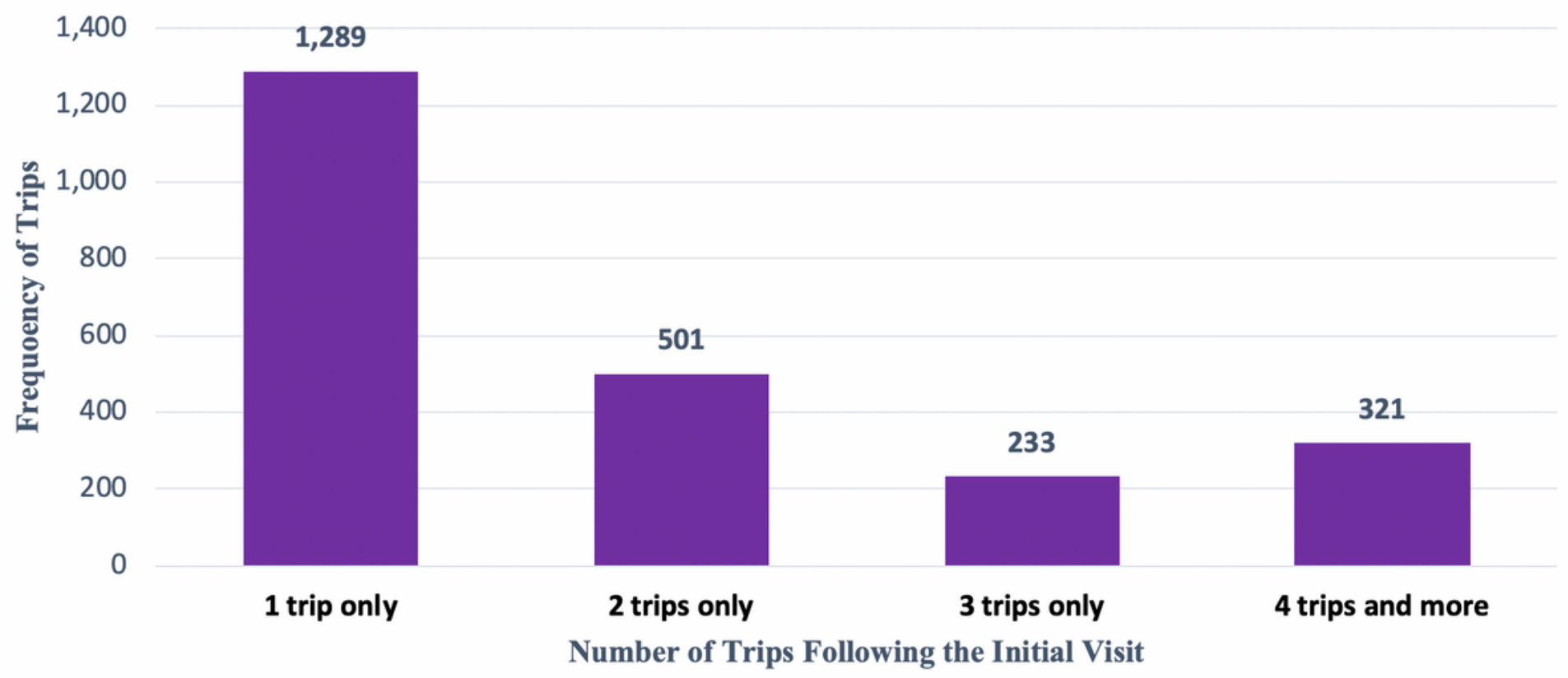

Figure 1

Distribution of trips following the initial trip among patients treated overseas from the United Arab Emirates sponsored by the Dubai Health Authority during 2019 - 2016. 